feel sure that those who were privileged to hear it must have left the theatre imbued with the highest ideals of life in a profession, which is above all others, altruistic, as set out by a much beloved master, whose life and work should be an inspiration to all medical students.

\title{
Intracapsular Extraction
}

The battle between intracapsular extraction of cataract and extraction with capsulotomy, and subsequent needling if necessary, has been waged for some years past. The policy of this journal has always been not to take sides in this matter. We admit that for the Indian peasant a single operation has its advantage; but in this matter, "East is east and West is west," and the advocates of the Indian operation must allow the majority of surgeons in England to go on in the old-fashioned manner until it has been shown that the operation, in the hands of the average English surgeon, is as safe as the older methods have been proved to be. The enormous operative experience of Indian surgeons is admitted. In this country probably no surgeon has the opportunity of performing a tithe of the number of extractions performed in the big Indian centres in the course of a single year.

The paper by Dr. Conor O'Malley in the current number raises the question anew; in it he is mainly concerned with the method of lens delivery per se; he considers that as it is comparatively successful in spite of conditions which would seem to militate against it, it must have some intrinsic merit.

Our readers may possibly take exception to certain points, such as the entire lack of bacteriological examination of the field of operation prior to the extraction; the fact that two eyes are operated on, if need be, at a single sitting; and that some lenses, apparently with very little opacity as seen after extraction, were removed. With regard to this last point the author admits that his statement is liable to misconstruction; he saw no transparent lens, or one with incipient cataract extracted; he wishes to emphasise the fact that it is not necessary to wait for maturity in cases where the opacity is causing serious defects of vision.

The operating season in a rural clinic in India such as the one he worked in is only of about five weeks' duration; there are only one surgeon and three qualified assistants. Patients come in hundreds and if they are not operated on at once, they leave, never to return. Were bacteriological examination attempted as a routine it would mean that 90 per cent. of cases would return to their homes without any operation at all.

It will be seen that conditions in a rural clinic in India cannot be compared with those in this country; we should think that visual 
conditions differ very much also. We suppose the average ryot is unable to read; he certainly does not need a high grade of macular vision for detail in his work. It is obvious that the average agricultural labourer uses his binocular field rather than his actual macular vision when at work; and we, who think of vision in terms of Snellen's test-types, must remember that what a peasant needs is such a grade of vision as is necessary for us to tell, say, a cabbage from an onion, at his usual working distance. We are not prepared to say how large an angle a rice plant forms at a working distance of, e.g., three feet, but we know that the width of the binocular field is about 184 degrees in the horizontal meridian, whereas the area of uniocular macular vision subtends an angle of about two degrees.

The fact that many of these Indian rural patients return to work after extraction of cataract without any glasses is evidence that only a very low grade of macular vision is necessary for their work. Most of these patients cannot afford the cost of a pair of glasses and apparently get on quite well without them. A similar state of affairs is still seen occasionally in this country among miners and labourers. Freeland Fergus has reported the case of a miner at work at the coal face, with more than twenty dioptres of myopia, and yet able to earn good wages without wearing glasses.

Everyone is aware of the fact that extensive peripheral opacities may be present in the lens without seriously impairing vision and that much less opacity in or about the visual axis may cause great disturbance of vision. We should imagine that the average ryot could still see to do his work with a larger measure of peripheral opacity than an artizan in other countries, and that when he can no longer see to work his cataract must, in most instances, be well on the way to maturity.

In the question of choice of method of removal of cataract the attitude should be adopted of "Live and let live." It is neither possible nor expedient to try and standardise operative procedures to a single method which shall hold good for all cases. All we ask is that the Indian exponents will allow us the same latitude of choice over here as we should be prepared to give them over there. It will be a poor day for ophthalmology if we are ever debarred from free choice of operative methods, for it is inconceivable that we are within reach of that Utopian state of affairs where everything has been reduced to its best-we should be standing still, no progress would be made; a state of affairs which is not yet in view. 